\title{
Papers
}

\section{Bezafibrate in men with lower extremity arterial disease: randomised controlled trial}

Tom Meade, Riaz Zuhrie, Claire Cook, Jackie Cooper on behalf of MRC General Practice Research Framework

\begin{abstract}
Objective To assess the effect of bezafibrate on the risk of coronary heart disease and stroke in men with lower extremity arterial disease.

Design Double blind placebo controlled randomised trial.

Setting 85 general practices and nine hospital vascular clinics.

Participants 1568 men, mean age 68.2 years (range 35 to 92$)$ at recruitment.

Interventions Bezafibrate $400 \mathrm{mg}$ daily (783 men) or placebo (785 men).

Main outcome measures Combination of coronary heart disease and of stroke. All coronary events, fatal and non-fatal coronary events separately, and strokes alone (secondary end points).

Results Bezafibrate did not reduce the incidence of coronary heart disease and stroke. There were 150 and 160 events in the active and placebo groups respectively (relative risk $0.96,95 \%$ confidence interval 0.76 to 1.21 ). There were 90 and 111 major coronary events in the active and placebo groups respectively $(0.81,0.60$ to 1.08$)$, of which 64 and 65 were fatal $(0.95,0.66$ to 1.37$)$ and 26 and 46 non-fatal $(0.60,0.36$ to 0.99$)$. Beneficial effects on non-fatal events were greatest in men aged $<65$ years at entry, in whom benefit was also seen for all coronary events $(0.38$, 0.20 to 0.72 ). There were no significant effects in older men. There were 60 strokes in those on active treatment and 49 in those on placebo (1.34, 0.80 to 2.01). There were 204 and 195 deaths from all causes in the two groups respectively (1.03, 0.83 to 1.26$)$. Bezafibrate reduced the severity of intermittent claudication for up to three years.

Conclusions Bezafibrate has no effect on the incidence of coronary heart disease and of stroke combined but may reduce the incidence of non-fatal coronary events, particularly in those aged $<65$ years at entry, in whom all coronary events may also be reduced.
\end{abstract}

\section{Introduction}

Evidence from epidemiological research has shown strong associations between high plasma fibrinogen concentrations and the onset and progression of arterial disease at all three main sites-that is, heart, brain, and lower extremities. ${ }^{1-3}$ High concentrations are also associated with venous thrombosis ${ }^{4}$ and may impair the outcome of percutaneous coronary angioplasty. ${ }^{5}$ Fibrinogen affects several pathways involved in thrombogenesis. ${ }^{6}$ This evidence suggests that high fibrinogen concentrations are an important cause. On the other hand, the effects of lowering concentrations need to be established through randomised trials so that not only can the role of fibrinogen be clarified but also any clinical implications defined.

Apart from ancrod, which has to be given by infusion, there are no drugs available that selectively lower fibrinogen concentrations. However, several fibrates lower concentrations as well as modifying lipid profiles, for which they were originally introduced. (If any clinical benefits of bezafibrate could be apportioned between its effects on fibrinogen and on lipids we would be able to clarify the part played by fibrinogen in altering the risk of coronary heart disease.)

To establish any benefits, the lower extremity arterial disease event reduction (LEADER) trial of bezafibrate was carried out in men with lower extremity arterial disease. This condition was selected partly because raised triglyceride concentrations may contribute to $\mathrm{it}^{7}$ and the greatest effect of bezafibrate is to lower triglycerides, but also because of the high incidence of coronary heart disease events and strokes in such patients.

\section{Methods}

The trial was carried out in men on the lists of 85 practices throughout the United Kingdom in the Medical Research Council's general practice research framework and in nine hospital vascular clinics. Entry from another vascular clinic was discontinued because of unreliable and poor quality data, which were discarded. Recruitment to the trial started in 1992 and was mainly completed in 1997 with a few further entrants in 1998. Follow up ended in September 2001. Identification of men with possible lower extremity arterial disease (confirmed with the Edinburgh claudication questionnaire), eligibility criteria, and the recruitment process including blood tests at entry have been described in full detail elsewhere ${ }^{8}$ (http://cvm.controlledtrials.com/content/2/4/195). Active treatment was bezafibrate $400 \mathrm{mg}$ daily (as Bezalip Mono, Roche) for men with creatinine plasma concentrations $<135$
Department of
Epidemiology and
Population Health,
London School of
Hygiene and
Tropical Medicine,
London
WC1E 7HT
Tom Meade
emeritus professor of
epidemiology
MRC Epidemiology
and Medical Care
Unit, Wolfson
Institute of
Preventive
Medicine, London
EC1M 6BQ
Riaz Zuhrie
clinical scientific
officer
Claire Cook
statistician
Jackie Cooper
statistician
Correspondence to:
T Meade
Tom.meade@
lshtm.ac.uk
bmj.com 2002;325:1139 


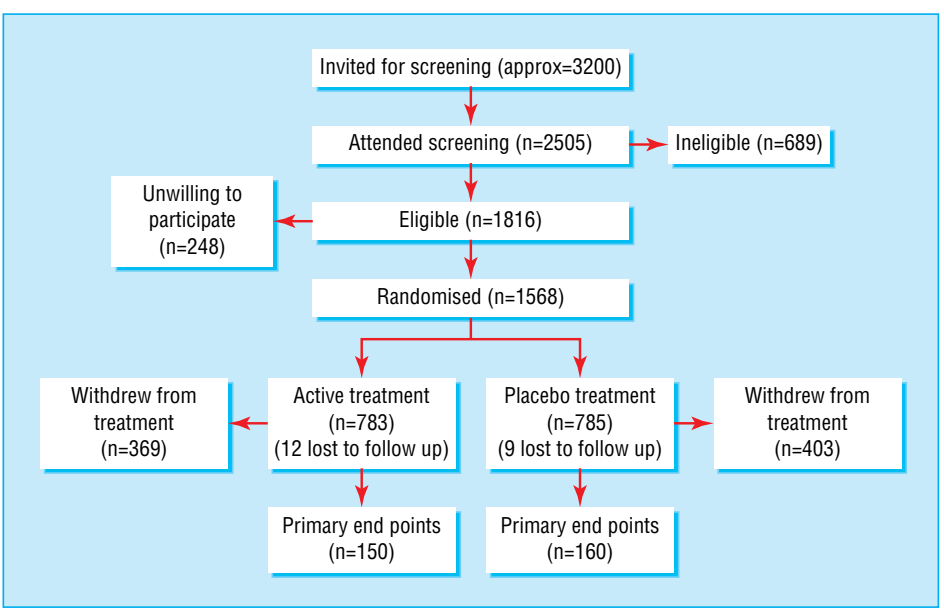

Fig 1 Recruitment of men with lower extremity arterial disease

Table 1 Reasons for exclusion or refusal in 937 of 2505 men screened

\begin{tabular}{lc} 
& No of men \\
\hline LEAD not confirmed & 277 \\
\hline Patient unwilling & 248 \\
\hline Lipid modifying agent & 87 \\
\hline Blood test results & 64 \\
\hline Renal or hepatic disease & 45 \\
\hline Other significant disease & 36 \\
\hline Unstable angina & 17 \\
\hline Malignant disease & 16 \\
\hline Died before trial entry & 15 \\
\hline Other, unknown & 132 \\
\hline Total & 937 \\
\hline
\end{tabular}

LEAD=lower extremity arterial disease.

${ }^{*}$ At screening - for example, raised creatinine concentration.

$\mu \mathrm{mol} / \mathrm{l}$. The placebo group received tablets identical in appearance. Men with creatinine concentrations of $135-149 \mu \mathrm{mol} / \mathrm{l}$ at entry took $400 \mathrm{mg}$ on alternate

Table 2 Characteristics of 1568 men entering trial. Figures are numbers (percentage) unless stated otherwise

\begin{tabular}{|c|c|c|}
\hline & Active $(n=783)$ & Placebo $(n=785)$ \\
\hline Mean (SD) age (years) & $68.4(8.9)$ & $68.0(8.8)$ \\
\hline \multicolumn{3}{|l|}{ Smoking: } \\
\hline Current & $306(39.1)$ & $287(36.6)$ \\
\hline Former & $447(57.1)$ & $460(58.6)$ \\
\hline Never & $30(3.8)$ & $38(4.8)$ \\
\hline \multicolumn{3}{|l|}{ History*: } \\
\hline Myocardial infarction & $151(20.5)$ & $160(21.7)$ \\
\hline Stroke & $95(12.9)$ & $88(11.9)$ \\
\hline Stable angina & $176(22.5)$ & $200(25.5)$ \\
\hline None & $444(60.4)$ & $420(56.8)$ \\
\hline \multicolumn{3}{|l|}{ Mean (SD) blood pressure $(\mathrm{mm} \mathrm{Hg})$ : } \\
\hline Systolic & $148.4(22.6)$ & $148.0(21.9)$ \\
\hline Diastolic & $77.2(11.9)$ & $77.6(11.4)$ \\
\hline Diabetes† & $137(17.5)$ & $131(16.7)$ \\
\hline Antiplatelet medication $\ddagger$ & $484(65.9)$ & $482(65.2)$ \\
\hline Median (IQR) fibrinogen concentration (g/l) & $3.37(2.96-3.76)$ & $3.35(2.99-3.74)$ \\
\hline \multicolumn{3}{|l|}{ Median (IQR) cholesterol concentration (mmol/l): } \\
\hline Total & $5.6(5.0-6.3)$ & $5.6(5.0-6.2)$ \\
\hline Low density lipoprotein & $3.37(2.78-3.97)$ & $3.40(2.85-3.96)$ \\
\hline High density lipoprotein & $1.11(0.95-1.40)$ & $1.13(0.95-1.37)$ \\
\hline Median (IQR) triglyceride concentration ( $\mathrm{mmol} / \mathrm{l})$ & $2.11(1.53-3.01)$ & $2.15(1.56-2.89)$ \\
\hline
\end{tabular}

$\mathrm{QR}=$ =interquantile range.

Some men had more than one condition, and for some data were missing

†Treatment: $24 \%$ on insulin, $57 \%$ on oral therapy; $22 \%$ diet only.

Treatment: $95 \%$ on aspirin, $5 \%$ on dipyridamole. For some men data were missing. days. In men taking daily treatment (that is, creatinine $<135 \mu \mathrm{mol} / \mathrm{l}$ at entry) this was changed to alternate day treatment if concentrations rose to $155 \mu \mathrm{mol} / \mathrm{l}$ unless and until concentrations rose to $\geqslant 170 \mu \mathrm{mol} / \mathrm{l}$, in which case men were withdrawn from trial treatment. These changes were made for all men, whether they were on active or placebo treatment.

The trial was approved by the local research ethics committees responsible for the participating practices and hospitals. The question most frequently raised before final approval was given (in the early and mid-1990s) was whether men should routinely be taking statins. How this point was settled is described elsewhere. ${ }^{8}$

Full details about follow up and ascertainment of end points are also available elsewhere. ${ }^{8}$ All deaths were notified from the NHS central register. Details on non-fatal events were unavailable for only 21 (1.3\%) men.

\section{Analysis}

The primary end point was the combination of all coronary heart disease events (non-fatal and fatal) and all strokes. At an early stage in the trial and well before any analyses of the main results, we defined all coronary events and fatal and non-fatal events and stroke separately as secondary end points because of results from other trials. On assumptions given in detail elsewhere $^{8}$ we calculated that we could detect a reduction of $30 \%$ in the primary end point due to bezafibrate in 1500 men at $5 \%$ level of significance with $80 \%$ power. We used entry characteristics in Cox regressions to estimate relative risks. However, these regressions made little difference to the unadjusted risks.

Analysis of results on clinical end points was on an intention to treat basis, with all first end point events up till September 2001 being assigned to originally allocated treatment groups, whether or not men had withdrawn from treatment at any stage. (Deaths from all causes include those occurring after first end point events, so ratios are based on more person years than shown.)

\section{Results}

\section{Recruitment}

Recruitment is illustrated in fig 1 . Of about 3200 men invited to attend the first or screening visit (precise numbers not recorded), either in the framework or in the hospitals, 2505 did so. Of these, we excluded 937

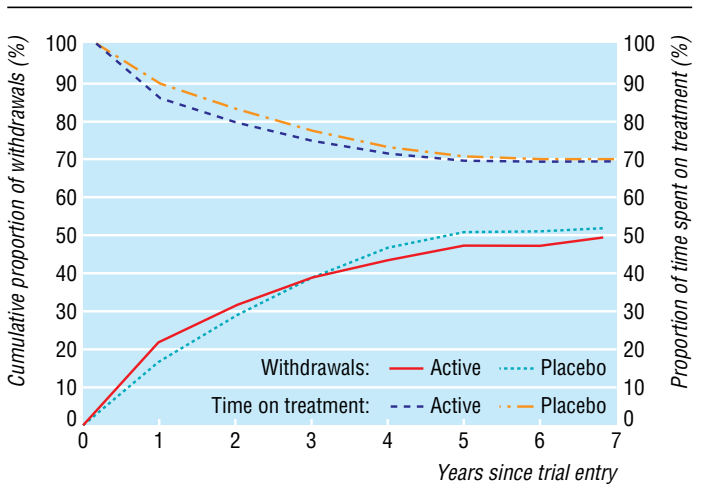

Fig 2 Withdrawals from and time on randomised treatment 
(37\%) at screening, at the baseline medical examination, or at trial entry for the reasons shown in table 1 . The 1568 patients randomised represent $86 \%$ of the 1816 eligible participants, and their characteristics are given in table 2, which shows that the two randomised groups were similar. At entry concentrations of fibrinogen and lipids were not grossly abnormal. The median follow up period was 4.6 years (range 3.1 to 7.8 years). The cumulative proportions withdrawn according to time from entry are shown in fig 2. Many withdrawals took place after several years' participation on randomly assigned treatment so that $70 \%$ of person years were spent on allocated treatment. Results from alkaline phosphatase tests indicated a high level of compliance in participants who continued with treatment. ${ }^{8}$ The total proportions who withdrew were similar in the two groups. However, significantly more men in the placebo group withdrew because they started a drug treatment incompatible with bezafibrate, nearly always a statin, and significantly more men in the active treatment group were withdrawn because of raised creatinine concentrations (table 3 ).

The effects of active treatment on concentrations of lipids, fibrinogen, creatinine, and alkaline phosphatase have been considered fully elsewhere. ${ }^{8}$ Final overall results were a reduction in total cholesterol of $7.6 \%$ (95\% confidence interval $6.7 \%$ to $8.6 \%$ ) and in low density lipoprotein cholesterol of $8.1 \%$ (6.5\% to $9.8 \%)$ and a rise in high density lipoprotein cholesterol of $8.0 \%$ (6.4\% to $9.6 \%)$. Triglyceride concentration was reduced by $23.3 \%(20.6 \%$ to $26.0 \%)$ and fibrinogen by $13 \%(11.7 \%$ to $14.4 \%)($ all $\mathrm{P}<0.0001)$.

The main results are summarised in table 4 and fig 3. There was no effect of treatment on the combined incidence of coronary heart disease and stroke, with 150 and 160 events in those in the active and placebo groups, respectively (relative risk $0.96,95 \%$ confidence interval 0.76 to $1.21, \mathrm{P}=0.72$ ). When we considered fatal and non-fatal coronary heart disease together, there were 90 events on active and 111 events on placebo treatment, a reduction of $19 \%(0.81,0.60$ to 1.08 , $\mathrm{P}=0.15)$. This result is the net effect of 64 and 65 fatal events in the two groups $(\mathrm{P}=0.79)$ and 26 and 46 nonfatal events, a reduction of $40 \%(0.60,0.36$ to 0.99 , $\mathrm{P}=0.05)$.

There were 60 strokes in those on active treatment compared with 49 in the placebo group, an excess of $34 \%$ in those on active treatment ( 0.80 to $2.01, \mathrm{P}=0.49$ ). There were 13 fatal strokes in the active treatment group and nine in the placebo group $(\mathrm{P}=0.67)$ and 47 and 40 for non-fatal events respectively $(\mathrm{P}=0.19)$.

Table 5 shows that in men aged $<65$ years at entry bezafibrate reduced the incidence of non-fatal coronary events. Also, all events, fatal and non-fatal combined, were $62 \%$ lower than in the placebo group $(0.38,0.20$ to 0.72$)$.

The Edinburgh claudication questionnaire assesses severity of claudication to some extent by recording whether pain occurs only when the patient is walking up hill or hurrying or if it also occurs both then and on walking at an ordinary pace on the level. There was some improvement in the placebo group, but bezafibrate resulted in a significantly greater improvement from baseline at one, two, and three years though not thereafter (table 6). (Degree of severity was not
Table 3 Reasons for withdrawal from treatment. Figures are numbers (percentage) of participants

\begin{tabular}{lccc} 
& Active $(\mathbf{n}=\mathbf{7 8 3})$ & Placebo $(\mathbf{n}=\mathbf{7 8 5})$ & P value \\
\hline Disease requiring cessation of treatment & $28(3.6)$ & $28(3.6)$ & 0.99 \\
\hline Drug incompatible with bezafibrate & $42(5.4)$ & $109(13.9)$ & $<0.0001$ \\
\hline Excessive adverse reaction & $36(4.6)$ & $30(3.8)$ & 0.44 \\
\hline Other relevant condition & $29(3.7)$ & $39(5.0)$ & 0.22 \\
\hline Non-compliance & $5(0.6)$ & $5(0.6)$ & 0.99 \\
\hline Moved away & $11(1.4)$ & $8(1.0)$ & 0.49 \\
\hline No longer wants to participate & $144(18.4)$ & $122(15.5)$ & 0.13 \\
\hline Other & $49(6.3)$ & $57(7.3)$ & 0.43 \\
\hline Raised creatinine concentration & $25(3.2)$ & $5(0.6)$ & $<0.0001$ \\
\hline Total & $369(47.1)$ & $403(51.3)$ & 0.10 \\
\hline
\end{tabular}

Table 4 Number of events and rates/1000 person years* according to randomly

allocated treatment and relative risks ( $95 \%$ confidence interval)

\begin{tabular}{|c|c|c|c|c|c|c|}
\hline & \multicolumn{2}{|c|}{$\begin{array}{c}\text { Active }(\mathrm{n}=783 \\
3029 \text { person years) }\end{array}$} & \multicolumn{2}{|c|}{$\begin{array}{c}\text { Placebo ( } n=785 ; \\
3076 \text { person years) }\end{array}$} & \multirow[b]{2}{*}{ RR $(95 \%$ Cl)† } & \multirow[b]{2}{*}{$P$ value } \\
\hline & Events & Rate & Events & Rate & & \\
\hline All primary end points & 150 & 49.5 & 160 & 52.0 & $0.96(0.76$ to 1.21$)$ & 0.72 \\
\hline \multicolumn{7}{|l|}{ Coronary heart disease: } \\
\hline Fatal & 64 & 21.1 & 65 & 21.1 & 0.95 (0.66 to 1.37$)$ & 0.79 \\
\hline Non-fatal & 26 & 8.6 & 46 & 15.0 & $0.60(0.36$ to 0.99$)$ & 0.05 \\
\hline All & 90 & 29.7 & 111 & 36.1 & 0.81 (0.60 to 1.08$)$ & 0.15 \\
\hline \multicolumn{7}{|l|}{ Stroke: } \\
\hline Fatal & 13 & 4.3 & 9 & 2.9 & $1.24(0.46$ to 3.37$)$ & 0.67 \\
\hline Non-fatal & 47 & 15.5 & 40 & 13.0 & $1.34(0.86$ to 2.10$)$ & 0.19 \\
\hline All & 60 & 19.8 & 49 & 15.9 & 1.34 (0.80 to 2.01$)$ & 0.49 \\
\hline Deaths, all causesł & 204 & 63.9 & 195 & 59.6 & 1.03 (0.83 to 1.26$)$ & 0.81 \\
\hline
\end{tabular}

${ }^{*}$ Calculated as time to first event or time in trial for event-free men.

†Adjusted for entry characteristics.

†Mainly cancer (47 active treatment, 47 placebo), heart failure, and respiratory disease (see text).

Table 5 Number of coronary heart disease events and rates/1000 person years according to randomly allocated treatment and adjusted relative risks ( $95 \%$ confidence intervals) by age at entry

\begin{tabular}{|c|c|c|c|c|c|}
\hline \multirow[b]{2}{*}{ Age } & \multicolumn{2}{|c|}{ Active } & \multicolumn{2}{|c|}{ Placebo } & \multirow[b]{2}{*}{ RR (95\% CI) } \\
\hline & Events & Rate & Events & Rate & \\
\hline \multicolumn{6}{|c|}{ Non-fatal ${ }^{*}$} \\
\hline$<65$ & 4 & 4.0 & 18 & 17.6 & $0.13(0.03$ to 0.56$)$ \\
\hline $65-74$ & 14 & 10.5 & 20 & 15.1 & 0.73 (0.36 to 1.47$)$ \\
\hline$\geqslant 75$ & 8 & 11.6 & 8 & 11.0 & $1.40(0.47$ to 4.21$)$ \\
\hline \multicolumn{6}{|l|}{ Fatalt } \\
\hline$<65$ & 13 & 13.0 & 20 & 19.5 & $0.57(0.27$ to 1.21$)$ \\
\hline $65-74$ & 24 & 17.9 & 24 & 18.1 & 0.98 (0.54 to 1.78$)$ \\
\hline$\geqslant 75$ & 27 & 39.1 & 21 & 28.8 & 1.49 (0.82 to 2.72$)$ \\
\hline \multicolumn{6}{|l|}{ All } \\
\hline$<65$ & 17 & 17.0 & 38 & 37.1 & 0.38 (0.20 to 0.72$)$ \\
\hline $65-74$ & 38 & 28.4 & 44 & 33.2 & 0.87 (0.55 to 1.37$)$ \\
\hline$\geqslant 75$ & 35 & 50.7 & 29 & 39.8 & 1.47 (0.87 to 2.48$)$ \\
\hline
\end{tabular}

Test for age (continuous variable) and treatment interaction: ${ }^{*} \mathrm{P}=0.02, \mathrm{\dagger}=0.11, \ddagger \mathrm{P}=0.01$.

recorded at baseline for $192(12 \%)$ men, with equal numbers in the two treatment groups.)

\section{Discussion}

We found that bezafibrate had no significant effect on our primary end point of coronary heart disease and stroke combined. For various possible reasons ("healthy volunteer" effect, variability of data for determining the required sample size, increasing statin use in the placebo group) the incidence of primary end points was less than that estimated. In particular, there were far fewer non-fatal events than we expected. This is unlikely to have been due to incomplete ascertainment as the methods for identifying and reporting end 

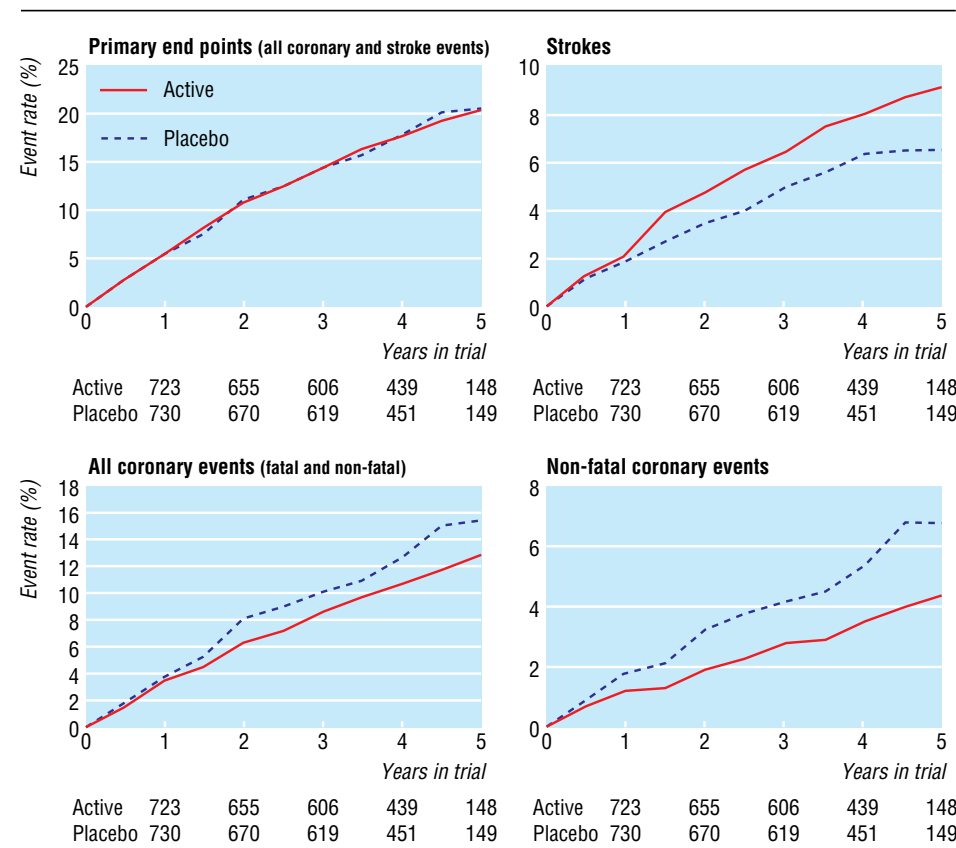

$\begin{array}{lllll}\text { Placebo } 730 & 670 & 619 & 451 & 149\end{array}$

Placebo $730 \quad 670 \quad 619-451-149$

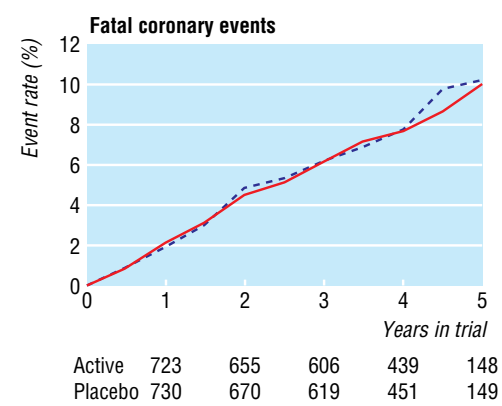

Fig 3 Proportion of men who experienced end points during trial: totals at baseline were 783 in active treatment group and 785 in placebo group

points were identical to those in other trials in the framework, ${ }^{9-11}$ in which the proportions of fatal and non-fatal episodes have been as expected. Apart from chance, one possibility is a particularly high case fatality from heart attacks in these men with lower extremity arterial disease. Another is that two thirds of the men were taking platelet anti-aggregating agents,

Table 6 Changes in Edinburgh claudication questionnaire. Figures are percentage (numbers) of participants

\begin{tabular}{|c|c|c|c|}
\hline & Active & Placebo & $P$ value \\
\hline \multicolumn{4}{|l|}{1 Year: } \\
\hline Improved & $19.8(91)$ & $13.0(63)$ & \multirow{3}{*}{0.001} \\
\hline Same & 71.5 (329) & $72.3(350)$ & \\
\hline Worse & $8.7(40)$ & $14.7(71)$ & \\
\hline \multicolumn{4}{|l|}{2 Years: } \\
\hline Improved & $20.9(74)$ & $17.5(65)$ & \multirow{3}{*}{0.01} \\
\hline Same & 71.6 (254) & 67.5 (251) & \\
\hline Worse & $7.6(27)$ & $15.1(56)$ & \\
\hline \multicolumn{4}{|l|}{3 Years: } \\
\hline Improved & $19.2(54)$ & $18.9(57)$ & \multirow{3}{*}{0.02} \\
\hline Same & 71.9 (202) & 64.5 (194) & \\
\hline Worse & $8.9(25)$ & $16.6(50)$ & \\
\hline \multicolumn{4}{|l|}{ 4-6 Years: } \\
\hline Improved & $15.4(25)$ & $18.2(29)$ & \multirow{3}{*}{0.49} \\
\hline Same & 71.0 (115) & 64.8 (103) & \\
\hline Worse & $13.6(22)$ & $17.0(27)$ & \\
\hline
\end{tabular}

nearly all as aspirin, which may reduce non-fatal more than fatal events. ${ }^{9}{ }^{12}$

There were more strokes and deaths from all causes in those on active treatment than on placebo treatment, though neither of these differences was significant. However, there was a significant reduction of about $40 \%$ in the secondary end point of non-fatal coronary events among those allocated to active treatment. Besides our trial, two other trials of fibrates ${ }^{13-15}$ have shown greater treatment effects on non-fatal than fatal events. When we looked at deaths from all causes we found no adverse effect on cancer. Bezafibrate may have reduced the incidence of all coronary heart disease events, particularly non-fatal events, in men under 65 years at entry, the absolute benefit suggested being appreciable. We did not prespecify any possibility of an interaction between age and active treatment so any response to treatment by age should be considered in data from other trials. Our trial contributes to the cholesterol treatment trialists collaboration, ${ }^{16}$ which will include other trials that used fibrates, so this point can eventually be examined in analyses based on considerably larger numbers of events. Bezafibrate may improve the severity of claudication for a year or two.

\section{Other trials}

The bezafibrate infarction prevention trial in Israel recruited 3090 men and women aged 45 to 74 years with an established history of coronary heart disease. $^{13} 14$ The trial's underlying hypothesis was that bezafibrate would reduce rates of recurrence by raising concentrations of high density lipoprotein cholesterol and lowering triglyceride. Overall, the $9.4 \%$ reduction in the incidence of the combined primary end point of fatal or non-fatal myocardial infarction or sudden death was not significant. In those whose triglyceride concentrations at entry were $\geqslant 2.26 \mathrm{mmol} / \mathrm{l}$ (200 $\mathrm{mg} / \mathrm{dl}$ ), the nearly $40 \%$ reduction was significant $(\mathrm{P}=0.02)$ whereas there was no difference among those with lower concentrations. Our results, however, provide no support for the possibility raised by the Israeli trial of significant benefit among those with high triglyceride concentrations (data not shown).

The bezafibrate coronary atherosclerosis intervention trial (using bezafibrate $200 \mathrm{mg}$ three times daily) was carried out in 92 people aged $<45$ years who had survived a myocardial infarction. ${ }^{17}$ The main purpose of the trial was to see whether treatment could retard or prevent the progression of atherosclerotic lesions assessed by coronary angiography at baseline and then at two, three, and five years, which was achieved. In addition, three of the 47 patients receiving active treatment had coronary events compared with 11 of the 45 in the placebo group, a reduction of nearly $75 \%$ $(\mathrm{P}=0.019)$.

In the diabetes atherosclerosis intervention study that used micronised fenofibrate, angiographic progression of coronary artery disease was reduced by active treatment and there were 38 and 50 clinical end points among 207 on active and 211 on placebo treatment respectively, though the difference was not significant. $^{18}$

Two trials that used gemfibrozil, which has different properties compared with bezafibrate and fenofibrate, 


\section{What is already known on this topic}

The beneficial effects of bezafibrate on blood lipids and fibrinogen concentrations should reduce the incidence of heart attacks and strokes

So far, however, there is only limited evidence on clinical outcomes from randomised controlled trials

\section{What this study adds}

Treatment with bezafibrate was not associated with a reduction in the combined incidence of heart attacks and strokes, though there were substantially fewer non-fatal heart attacks in those taking bezafibrate

Bezafibrate was associated with a reduction in the incidence of all heart attacks, especially non-fatal, in men aged $<65$ years

Bezafibrate seems to reduce the severity of intermittent claudication for two or three years

showed that it significantly reduced the incidence of clinical end points. ${ }^{19} 20$

\section{Bezafibrate and homocysteine}

Bezafibrate increases homocysteine concentrations, ${ }^{21}$ and high concentrations are an important risk factor for vascular disease. A further trial could usefully see whether the concurrent use of folic acid and bezafibrate would allow its beneficial effects on fibrinogen and lipid profiles to reduce the risk of heart attacks and strokes to a worthwhile extent.

We thank the nurses and doctors in the following areas whose practices are in the general practice research framework: Abingdon, Alexandria, Ashstead, Ballycastle, Balsall Common, Barrow-in-Furness, Bath, Bedford, Belfast, Bovey Tracey, Bracknell, Brechin, Brewood, Bromsgrove, Bude, Bungay, Camberley, Carnforth, Comber, Crawley, Crediton, Cullompton, Darlington, Darwen, Deal, East Grinstead, Exmouth, Fleet, Fovant, Glasgow, Gosforth, Guildford, Guisborough, Hayfield, Herne Bay, Hildenborough, Horwich, Ilchester, Keadby, Kidderminster, Leeds, Lichfield, Lisburn, Liskeard, Brondesbury (London), Mansfield, Martock, Nailsea, Newmarket, Newtown, Northampton, Norwich, Ormskirk, Perth, Poole, Portadown, Queensferry, Rotherham, Rugby, Sheffield, Shipston-on-Stour, Southport, Tilehurst, Walsall, Wellingborough, Whitehaven, Wigston, Winterton, Woodley.

We also thank the staff at hospital vascular clinics at Northwick Park, Harrow; St Bartholomew's and London Chest, St Thomas's, Charing Cross, and Whipps Cross in London; Royal United Hospital, Bath; Royal Infirmary, Glasgow; Princess Royal Hospital, Telford; Royal Victoria Hospital, Belfast; and nursing colleagues in the MRC Epidemiology and Medical Care Unit, Wendy Browne, Anne Walgrove, and Louise Letley, who managed the training and day-to-day contacts with the practices and Ken Whyte and Wendy Quy, trial managers and data processing, and other unit staff involved.

Contributors: The trial was designed and implemented by TM (who is also guarantor), RZ, and CC and JC analysed the results.
Bianca De Stavola advised on statistical analyses. End point reports were assembled by Katherine Garrow, Christine Knottenbelt, and George Miller and independently assessed by John Dickinson. The data monitoring and ethics committee comprised S Pocock (chair), G Fowkes, and D Julian.

Competing interests: Trial tablets were supplied free of charge by Boehringer-Mannheim.

Funding: Medical Research Council and British Heart Foundation.

1 Danesh J, Collins R, Appleby P, Peto R. Association of fibrinogen, C-reactive protein, albumin, or leukocyte count with coronary heart disease: meta-analysis of prospective studies. JAMA 1998;279:1477-82.

2 Resch KL, Ernst E, Matrai A, Paulsen HF. Fibrinogen and viscosity as risk factors for subsequent cardiovascular events in stroke survivors. Ann Intern Med 1992;117:371-5.

3 Banerjee AK, Pearson J, Gilliland EL, Goss D, Lewis JD, Stirling Y, et al. A six year prospective study of fibrinogen and other risk factors associated with mortality in stable claudicants. Thromb Haemost 1992,68:261-3.

4 Koster T, Rosendaal FR, Reitsma PH, van der Velden PA, Briet E, Vandenbroucke JP. Factor VII and fibrinogen levels as risk factors for venous thrombosis. Thromb Haemost 1994;71:719-22.

5 Montalescot G, Ankri A, Vicaut E, Drobinnski G, Grosgogeat Y, Thoma D. Fibrinogen after coronary angioplasty as a risk factor for restenosis. Circulation 1995;92:31-8.

6 Meade TW. The epidemiology of atheroma, thrombosis and ischaemic heart disease. 3rd ed. In: Bloom AL, Forbes CD, Thomas DP, Tuddenham EGD, eds. Haemostasis and thrombosis. Edinburgh: Churchill Livingstone, 1994:1199-227.

7 Leng GC, Fowkes FGR. Lipids: epidemiology. In: Fowkes FGR, ed. Epide miology of peripheral vascular disease. London: Springer-Verlag, 1991:167-9.

8 Meade TW. Design and intermediate results of the lower extremity arterial disease event reduction (LEADER) trial of bezafibrate in men with lower extremity arterial disease. Curr Control Trials Cardiovasc Med 2001:2:195-204.

9 MRC General Practice Research Framework. Randomised trial of low-intensity oral anticoagulation with warfarin and low-dose aspirin in the primary prevention of ischaemic heart disease in men at increased risk. Lancet 1998;321:129-41.

10 Medical Research Council working party. MRC trial of treatment of mild hypertension: principal results. BMJ 1985;291:97-104.

11 MRC working party. Medical Research Council trial of treatment of hypertension in older adults: principal results. BMJ 1992;304:405-12.

12 Steering Committee of the Physicians Study Research Group. Final report on the aspirin component of the ongoing physicians study. N Eng JMed 1989;321:129-35.

13 BIP Study Group. Rationale and design of a secondary prevention trial of increasing serum high-density lipoprotein cholesterol and reducing trilycerides in patients with clinically manifest atherosclerotic beart dis glycerides in patients with clinically manifest atherosclerotic heart disease
(the bezafibrate infarction prevention trial). Am J Cardiol 1993;71:909-15.

14 BIP Study Group. Secondary prevention by raising HDL cholesterol and reducing triglycerides in patients with coronary artery disease. Circulation 2000;102:21-7.

15 Committee of Principal Investigators. Cooperative trial in the primary prevention of ischaemic heart disease using clofibrate. Heart $J$ 1978;1069-118.

16 Cholesterol Treatment Trialists' (CTT) Collaboration. Protocol for a prospective collaborative overview of all current and planned randomized trials of cholesterol treatment regimens. Am J Cardiol 1995;75:1130-4.

17 Ericsson CG, Hamsten A, Nilsson J, Grip L, Svane B, De Fair U. Angiographic assessment of effects of bezafibrate on progression of coronary artery disease in young male postinfarction patients. Lance 1996:347:849-53

18 Diabetes Atherosclerosis Intervention Study Investigators. Effect of fenofibrate on progression of coronary-artery disease in type 2 diabetes: the diabetes atherosclerosis intervention study, a randomised study. Lancet 2001;357:905-10.

19 Frick MH, Elo O, Haapa K, Heinonen OP, Heinsalmi P, Helo P, et al. Helsinki heart study: primary-prevention trial with gemfibrozil in middle-aged men with dyslipidemia. N Engl J Med 1987;317:1237-45.

20 Bloomfield Rubins H, Robins SJ, Collins D, Fye CL, Anderson JW, Elam $\mathrm{MB}$, et al for the Veterans Affairs High-Density Lipoprotein Cholesterol Intervention Trial Study Group. Gemfibrozil for the secondary
prevention of coronary heart disease in men with low levels of prevention of coronary heart disease in men with low leves
high-density lipoprotein cholesterol. N Engl J Med 1999;341:410-8.

21 Jonkers IJAM, de Man FHAF, Onkenhout W, van der Laarse A, Smelt AHM. Implication of fibrate therapy for homocysteine. Lancet 1999;354:1208.

(Accepted 8 August 2002) 